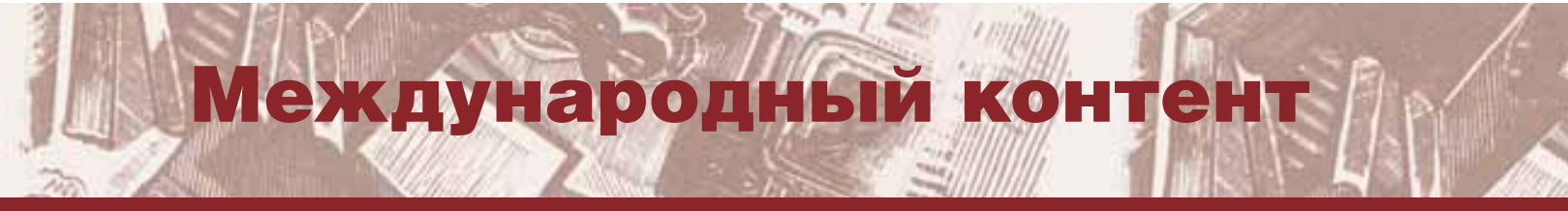

УДК 021(4/5)

ББК 78.34(051.9)

DOI 10.25281/0869-608X-2019-68-4-383-390

\section{Н.П. ИГУМНОВА}

\section{Библиотечное} пространство стран СНГ

\section{как самоорганизующаяся система: методология исследования}

Реферат. Раскрывается методология исследования библиотечного пространства Содружества Независимых Государств (СНГ), основанная на теории самоорганизации (синергетике). Синергетика как направление постнеклассической науки получила развитие в конце прошлого - начале нового тысячелетия в работах ряда исследователей, подтвердивших универсальность этой методологии и применимость ее к изучению процессов, протекающих в обществе. Тем не менее вплоть до 2000-х гг. она не получала достойного отражения в библиотековедении. Актуальность данного исследования состоит в том, что современному библиотековедению требуется новый мировоззренчески-методологический подход к изучению происходящих в культурной и библиотечной сфере процессов, который поможет развить и обогатить успешно применяемый метод системного анализа. Исходя из этого, ставится задача изучить библиотечное пространство СНГ как самоорганизующуюся систему, находящуюся в процессе эволюции в течение длительного исторического периода. Библиотечное пространство рассматривается как динамически развивающаяся система общественного характера. В историческом и современном аспектах прослежены ее причинно-следственные связи, условия и факторы. Понятие «библиотечное пространство СНГ» возникло после распада в 1991 г. Советского Союза и в результате образования СНГ для обозначения формы межгосударственного библиотечного взаимодействия и сотрудничества. Библиотечное пространство СНГ представлено как сформировавшаяся в постсоветское время система взаимодействия библиотек, основой которой является их принадлежность к Содружеству, внутри которого развиваются межгосударственные отношения библиотек; имеются длительные историко-культурные связи между ними, а русский язык является языком профессионального и межличностного общения. Дана описательная модель системы взаимодействия библиотек стран СНГ с основными признаками и принципами построения. Установлено, что библиотечному пространству СНГ присущи признаки сложной, открытой, динамической самоорганизующейся системы. Методологический характер и теоретико-философская значимость статьи делают ее интересной для библиотековедов, науковедов и культурологов.

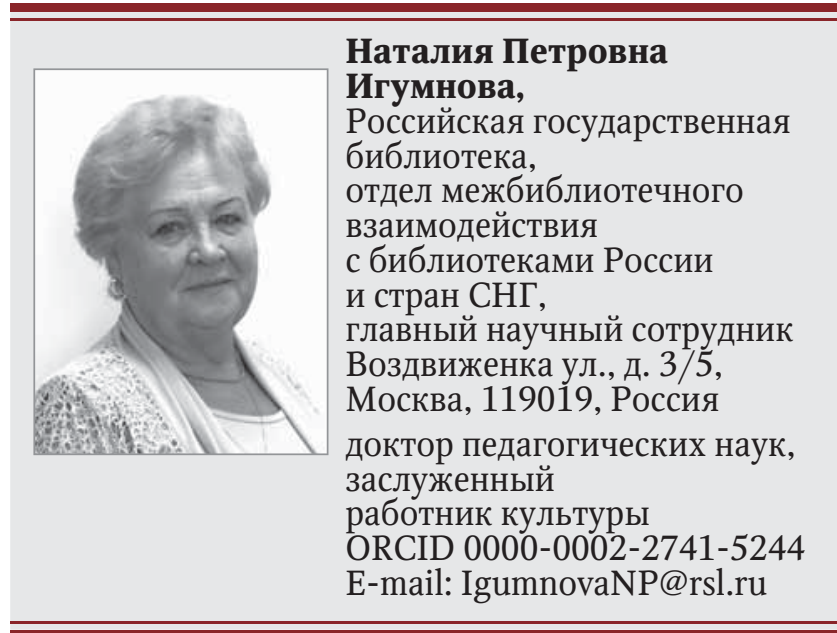


Ключевые слова: Содружество Независимых Государств, СНГ, библиотечное пространство, модель системы, историко-культурные связи, русский язык, условия, факторы, эволюция и развитие, теория библиотековедения, национальные библиотеки.

Для цитирования: Игумнова Н.П. Библиотечное пространство стран СНГ как самоорганизующаяся система: методология исследования // Библиотековедение. 2019. Т. 68, № 4. C. 383-390. DOI: 10.25281/0869-608X-2019-68-4-383-390.

$\Pi$ онятие «библиотечное пространство СНГ» возникло после распада в 1991 г. Союза Советских Социалистических $\mathrm{Pe}$ спублик (СССР) и в результате образования Содружества Независимых Государств (СНГ) для обозначения формы межгосударственного библиотечного взаимодействия и сотрудничества. Под ним подразумевалось объединение библиотек региона, необходимое для выживания этих институтов в условиях социально-политического и экономического кризиса и перехода к рыночной экономике, а также для обмена информацией и доступа к ней. Целью объединения было стратегическое планирование и выработка межгосударственной библиотечной политики, согласование позиций и решений по перспективным и злободневным проблемам библиотечной деятельности и этнокультурного взаимодействия. Эти проблемы возникли в равной степени у всех библиотек новых независимых государств, вошедших в состав СНГ, в начальный период самостоятельного развития. Объединение проходило с опорой на предшествующий, положительный опыт совместной работы и было направлено на дальнейшее ее развитие.

Использование синергетического подхода при изучении сложных объектов библиотековедения основывается на трудах крупных российских ученых. Синергетика как направление постнеклассической науки получила развитие в конце XX - начале XXI в. у Н.Н. Моисеева [1], Е.Н. Князевой и С.П. Курдюмова [2], которые подтвердили универсальность этой методологии и применимость ее к изучению процессов, протекающих в природе и в обществе.

Плодотворность использования синергетического подхода в культурологии показали О.Н. Астафьева [3], М.С. Каган [4], в демографии - С.П. Капица [5], в библиотековедении - Ю.Н. Столяров [6], М.Г. Вохрышева и T.М. Кузьмишина [7], Н.П. Игумнова [8].

Тем не менее вплоть до 2000-х гг. эта методология не получала достойного отражения в библиотековедении. Так, аналитики утверждали, что библиотечная наука находится в кризисном состоянии и не может преодолеть ограничения классического стиля мышления. Исследователи продолжают использовать преимущественно механистический подход, изучение статичных объектов, прежние методы научного эксперимента, количественного анализа, что не способствует определению новых ориентиров развития библиотечного дела [9]. Современному библиотековедению требуется новый мировоззренчески-методологический подход к изучению происходящих в культурной и библиотечной сфере процессов, который поможет развить и обогатить метод системного анализа, успешно применяемый в библиотековедческих исследованиях.

Этот подход предлагает постнеклассическое междисциплинарное направление науки синергетика, показывающее, что действие универсальных законов самоорганизации проявляется не только в естественно-научной области, но и в общественной жизни, а, значит, он применим и в конкретной профессиональной сфере деятельности. Поэтому была поставлена задача изучить библиотечное пространство как самоорганизующуюся систему, находящуюся в процессе эволюции в течение длительного исторического периода.

Академик Н.Н. Моисеев определил самоорганизацию как процесс изменения состояния сложной, отрытой и динамичной системы общественного характера на основе триады: постоянного изменения во времени (изменчивости), сохранения «памяти» системы, накопленного опыта (наследственности) и отбора из хаоса возможностей единственно правильного пути дальнейшего ее развития [1].

Рассмотрим, как данное теоретическое положение применимо к изучению эволюции библиотечного пространства, и покажем, что оно является сложной, отрытой и динамичной системой общественного характера.

Следует остановиться на понятиях «эволюция» и «развитие».

Учитывая множество определений понятия «эволюция», данных в энциклопедиях, словарях, а также в трудах ученых, мы взяли следующую интерпретацию понятия «эволюция библиотечного пространства». 
Эволюция библиотечного пространства процесс изменения качественного состояния системы библиотечного взаимодействия на основе механизмов сохранения предшествующего опыта и определения на каждом этапе соответствующих требованиям времени форм ее организации.

Под «развитием» мы понимаем непрерывный процесс формирования системы от возникновения предпосылок и условий до современных способов ее существования.

Понятие «библиотечное пространство СНГ» мы определяем как сложную систему взаимодействующих объектов - библиотек, библиотечных сетей, библиотечных объединений, библиотечных работников, деятельность которых направлена на удовлетворение множества информационных, культурно-просветительских, образовательных потребностей общества.

Библиотечное пространство стран СНГ является открытой системой, так как обладает следующими признаками:

- взаимодействует с объектами, входящими в систему, а также с внешними системами в области культуры, образования, книгоиздания, информатики и т. д.;

- оно восприимчиво к новым идеям, что повышает возможности динамического развития: например, ответом на внешнее воздействие процессов глобализации стало оперативное внедрение информационно-коммуникационных технологий в библиотеках для сохранения общего культурного и национального печатного и рукописного наследия, для расширения возможностей поиска документов;

- использует альтернативные формы взаимодействия: как двухстороннего характера при взаимодействии библиотек стран Балтии, Грузии, Украины с библиотеками стран СНГ, или, как при взаимодействии библиотек стран СНГ, многостороннего и интеграционного характера.

Библиотечное пространство СНГ является динамической системой. Оно находится в процессе эволюционного развития, т. е. постоянного изменения своего качественного состояния на основе механизмов самоорганизации: изменчивости в соответствии с закономерностями развития общества и библиотечного дела, наследственности - сохранения «памяти» системы, и отбора - в период кризиса выбора из «хаоса возможностей» (множества форм) новой формы организации библиотечного пространства.

Любая динамическая система имеет начало и конец, стремится к устойчивости. Так, за исходную позицию эволюции библиотечного про- странства на территории будущего СНГ можно принять состояние библиотечного дела во второй половине XIX в., когда Россия объединила вокруг себя евразийские народы в рамках единого государства. Библиотечное дело в Российской империи развивалось по общим правилам, наращивало количественные и качественные характеристики, обогащало организационные формы и направления деятельности.

Естественное развитие российского библиотечного пространства и его устойчивое состояние дважды кардинальным образом менялось под воздействием внешних факторов. Происходили эволюционные переломы с потерей устойчивости системы. Один - в период после революции 1917 г. до образования в 1922 г. Советского Союза, второй - с 1991 г. до создания Содружества Независимых Государств.

В 1922 г. с образованием СССР библиотечное пространство перешло к новой организационной форме - развитию единой государственной системы библиотек. В 1991 г. в результате ее распада возникла совершенно иная форма существования - система межгосударственного библиотечного взаимодействия.

Для описания процесса перехода системы в иное состояние в синергетике применяются понятия «бифуркации» и «хаоса». Бифуркация - пик кризиса системы, момент потери ее стабильности, когда нет возврата к исходному состоянию, но есть вероятность отбора из хаоса возможностей нового пути развития, при котором система снова достигает устойчивости. При этом новые формы не возникают на пустом месте, а базируются на сложившихся в предшествующий период. Новые и прежние организационные формы уравновешивают друг друга и не позволяют системе разрушиться. Как в первый, так и во второй период своего развития библиотечное пространство как система переходило на новый эволюционный путь развития, основываясь на организационных и содержательных достижениях прежнего времени.

При рассмотрении современной системы библиотечного пространства СНГ можно выделить три равнозначных ее признака:

- принадлежность стран, между которыми происходит межгосударственное библиотечное взаимодействие, к одному геополитическому пространству (СНГ) - политический признак;

- сформировавшаяся в ходе исторического развития библиотечного дела в рамках единого государства профессиональная и культурная общность - историко-культурный признак; 
- русский язык как язык межнационального и профессионального общения - лингвистический признак.

Библиотечное пространство СНГ обладает всеми признаками общности - согласованными на межгосударственном уровне общими принципами, целями, задачами, правилами, механизмами, которые не являются обязательными в каждой отдельной стране, а позволяют применять различные формы взаимодействия, использовать корпоративные и партнерские связи.

Для отслеживания состояния и поведения системы в периоды стабильного развития и на этапах эволюционного перелома, т. е. резкого перехода на новый путь развития, в теории самоорганизации вводится понятие «структураттракторов» эволюции. Их определение дается в публикации Е.Н. Князевой и С.П. Курдюмова [2]: «структуры-аттракторы» эволюции - это наиболее устойчивые образования, на которые неизбежно выходят процессы эволюции в открытых динамических системах. «Структуры-аттракторы» эволюции выступают в качестве механизма «преодоления» хаоса, перехода системы в устойчивое состояние. Поставленные в определенные условия, они реализуют одну из возможных организационных форм и определяют внутренние тенденции своего эволюционного развития, вырабатывают собственные предпочтения, которые заставляют их двигаться в нужном направлении.

В качестве «структур-аттракторов» эволюции библиотечного пространства выступали крупнейшие библиотеки (в сети публичных библиотек - Румянцевская и Императорская публичная библиотеки, в сети академических Библиотека Российской академии наук (БАН, до 1992 г. - Библиотека АН СССР), в сети вузовских - Библиотека МГУ и т. д.).

В постсоветское время «структурами-аттракторами» эволюции стали, прежде всего, государственные республиканские библиотеки, получившие статус национальных.

Определяющим фактором развития библиотечного пространства СНГ стал информационный обмен достижениями библиотечной науки и практики. Без информационного обмена не было бы и системы межгосударственного библиотечного взаимодействия в регионе. Обмен информацией стал способом взаимодействия ученых и библиотечных специалистов. Примером этого является деятельность Библиотечной Ассамблеи Евразии, отделения «Библиотековедение» Международной академии информатизации, а также опыт крымских и других междуна- родных конференций. Взаимодействие ученых и специалистов в процессе информационного обмена позволило им в новых условиях самостоятельного развития национальных библиотечных систем найти общий язык, выработать правила общения, создать возможности сотрудничества в совместных проектах и программах, что, в свою очередь, обеспечило рост научной информации в библиотечной сфере.

В конце 1980-х - начале 1990-х гг. расширился информационный обмен между странами мира, шел поиск наиболее выгодных партнерств. Образцом был высокий уровень технической оснащенности западноевропейских и американских библиотек.

Таким образом, мы установили, что библиотечному пространству СНГ присущи признаки сложной, открытой, динамической самоорганизующейся системы, состояние которой изменяется во времени в соответствии с закономерностями развития общества и библиотечного дела.

Установив, что библиотечное пространство СНГ может быть исследовано как самоорганизующаяся система, перейдем к описанию ее простой модели, удобной для понимания и использования.

Модель системы имеет следующие признаки.

1. Система состоит из взаимодействующих подсистем - структурных объектов и объектов деятельности. К структурным объектам мы относим библиотечные сети, объединения, библиотеки, библиотечно-информационные учебные заведения. К объектам деятельности библиотечную, информационную, культурнопросветительскую и иную деятельность, присущую библиотечной сфере.

2. В функционировании системы задействованы многие люди разных национальностей и гражданской принадлежности, с меняющимися интересами и настроениями (в том числе зависящими от политических обстоятельств), определяющими сложный характер их взаимоотношений друг с другом.

3. Внешние политические, экономические, социокультурные факторы оказывали влияние на происходящие в библиотечной сфере процессы и организационную структуру на протяжении всего времени существования системы.

Представление модели структурных объектов системы основывается на положении о том, что каждая подсистема или элемент системы (библиотека, библиотечное объединение 
и т. д.), является, в свою очередь, самостоятельной системой, имеет свои цели и характеристики ${ }^{1}$.

Модель строится на основании принципов:

- равного положения всех элементов системы по отношению друг к другу;

- реализации каждым элементом системы прежде всего собственных интересов, а не интересов системы, если они не совпадают с его интересами;

- общности интересов подсистем, которая выражается в формировании общего поля интересов и общего поля их взаимодействия.

Реализация данных принципов означает, что если подсистемы вступают во взаимодействие, то они имеют общее поле интересов, и наоборот, если общее поле интересов отсутствует, они не будут взаимодействовать.

Построение системы зависит от целей, а также механизмов и способов их достижения. Цели деятельности системы и ее подсистем могут совпадать, а могут отличаться. Если они совпадают, то включаются в общее взаимодействие. Например, в общее поле взаимодействия включены такие цели, как библиотечное законодательство, инновационная, просветительская, образовательная деятельность.

Механизмами взаимодействия являются взаимосвязи, сотрудничество, координация, кооперация и партнерство, достаточно разработаные в библиотековедении, на них можно не останавливаться.

Способами достижения результатов выступают соглашения, договора, программы, проекты, планы, реализуемые коллективами библиотек или специально созданными творческими группами. Примером могут служить Соглашение о создании Системы межбиблиотечного абонемента государств - участников СНГ [10], соглашения между отдельными библиотеками о сотрудничестве. Примерами проектов, осуществляемых на основе кооперации, являются «Золотая коллекция Евразии», «Издания и электронные ресурсы национальных библиотек СНГ», виртуальная выставка «Великая победа советского народа» (1941-1945 гг.), а также многие другие.

Исходным для исследования является положение, что библиотечное пространство СНГ как система определяет свойства своих подсистем: их способность к развитию разных форм взаимодействия; к инновациям, связанным, например, с использованием информационнокоммуникационных технологий; подготовлен- ностью библиотек к решению задач по корпоративному созданию электронных ресурсов, менеджменту, работе по этнокультурному сотрудничеству. От этих свойств подсистем зависят степень эффективности всей системы и ее стабильное развитие.

Следующим важным качеством развития рассматриваемой системы является ее взаимодействие с внешними системами: культурным, законодательным и другими пространствами СНГ, имеющими свои цели, структуру и содержание деятельности. Библиотеки в культурнопросветительной работе взаимодействуют с культурным пространством, при осуществлении информационной деятельности - с информационным, образовательной - с образовательным, законодательной - с законодательным пространством Содружества.

Это ярко проявляется, например, в участии библиотек и библиотечных объединений в культурных форумах, акциях (Год культуры, Год книги, дни культуры республик) или в подготовке модельного Библиотечного кодекса для государств - участников СНГ, основанного на модельных законах по информационной, гуманитарной, инновационной деятельности, этнокультурному взаимодействию, разработанных в рамках Содружества.

Таким образом, научный подход к исследованию библиотечного пространства СНГ как самоорганизующейся системы и выявлению ее свойств позволил сделать ряд теоретических выводов. $\mathrm{CHГ:}$

Общее библиотечное пространство стран

- представляет собой сферу профессионального взаимодействия, интегрирующую интересы библиотек, и является закономерно обусловленным результатом эволюции постсоветского библиотечного пространства, а его развитие подчиняется единой логике самоорганизации динамических систем и отражает реальное, проверяемое практикой явление общественной и культурной жизни;

- формируется для выработки согласованной библиотечной политики, общих направлений деятельности, корпоративного создания электронных информационных ресурсов, беспрепятственного обмена информацией с использованием современных информационных коммуникационных технологий;

- основывается на идее сохранения общего культурного наследия, на предшествующем опыте совместной деятельности, на теоретико- 
методологической базе научных школ библиотечного дела, общности интересов;

- реализуется путем совместных согласованных действий.

Изучение библиотечного пространства СНГ с использованием методологии универсального эволюционизма (синергетики) позволило охарактеризовать данное явление как систему, проследить его системные свойства, причинно-следственные связи как внутри системы, так и с внешним миром.

В настоящее время формируется новая парадигма развития библиотек, концептуальных основ и взглядов на их будущее, что характерно для всех стран СНГ. В связи с этим как минимум два вопроса, связанные с темой данной статьи, требуют научной проработки и не могут быть решены только в рамках библиотековедения. Речь идет о сохранении книги в традиционной бумажной форме и чтении печатного текста как основном процессе получения знания и развития интеллекта.

В профессиональной среде и в обществе в целом обсуждается тема полного вытеснения печатных форм электронными, и никакие прогнозы в этой связи сегодня не могут быть точными. На практике мы видим, что процессы изменения традиционной библиотеки и чтения проходят достаточно активно, часто произвольно, а ускорение их небезопасно. Законы самоорганизации общественного развития и библиотечного пространства будут продолжать действовать, и их последствия надо отслеживать, в том числе и в научном плане.

Второй вопрос касается классификации библиотековедения и, соответственно, подготовки специалистов в этой области. В 1990-х гг. теоретики отказались от разделения библиотековедения на «советское» и «несоветское», т. е. зарубежное. При этом в разделе общего библиотековедения теоретические, исторические и организационные проблемы библиотечной деятельности, вопросы терминологии, место в системе наук, связи с различными научными дисциплинами рассматриваются, главным образом, на отечественном материале.

Зарубежное (мировое) библиотековедение ушло из поля зрения профессионалов, а его также необходимо изучать. Если же говорить о теоретических основах развития библиотечного пространства СНГ, то они исследуются в разделе общего бибиотековедения, так как мы имеем общие научные школы, историю развития, сходные мировоззренческие установки. И это правильно. Библиотековедческая мысль требует дальнейшего развития, определения основных закономерностей и тенденций мирового библиотечного пространства и их отражения в общем библиотековедении.

\section{Примечание}

1 Система включает и другие подсистемы - объекты разнообразной деятельности библиотек: библиотечная, библиографическая, информационная, просветительская, этнокультурная, организационно-управленческая, научно-исследовательская деятельность. Данные подсистемы являются также законченными образованиями, занимающими свое место среди объектов системы, имеют свои цели и характеристики. Они также являются исторически развивающимися, открытыми и сложными системами.

\section{Список источников}

1. Моисеев Н.Н. Универсум. Информация. Общество. Москва : Устойчивый мир, 2001. 200 с.

2. Князева Е.Н., Курдюмов С.П. Основания синергетики. Человек, конструирующий себя и свое будущее. Москва : КомКнига. 2006. 232 с.

3. Астафъева О.Н. Синергетика, философия, культура // Государственная служба. 2001. № 2. C. $32-43$.

4. Каган М.С. Синергетика и культурология // Синергетика и методы науки : [сб. ст.]. СанктПетербург : Наука, 1998. С. 201-219.

5. Капииа С.П. Общая теория роста человечества: сколько людей жило, живет и будет жить на Земле. Москва : Наука, 1999. 190 с. (Кибернетика: неограниченные возможности и возможные ограничения).

6. Столяров Ю.Н. Синергийный подход в библиотековедении, библиографоведении, книговедении: когда и зачем он нужен // Библиотека и ассоциации в меняющемся мире: новые технологии и новые формы сотрудничества : труды 10-й Юбилейной междунар. конф. «Крым 2003». Москва : ГПНТБ, 2003. Т. 2. С. 760-763.

7. Вохрышева М.Г., Кузьмишина Т.М. Процесс развития современных библиотек с позиции синергетики // Научные и технические библиотеки. 2003. № 6. C. 4-13.

8. Игумнова Н.П. Евразийское библиотечное пространство в библиотечной политологии : монография. Москва : Пашков дом, 2014. 133 с.

9. Библиотечные исследования в системе постнеклассической науки : проблемно-ориентированный 
сборник / Рос. гос. б-ка ; [сост.: Е.В. Никонорова, М.И. Акилина]. Москва : Пашков дом, 2008. 271 с.

10. Положение о системе межбиблиотечного абонемента и доставки документов : утверждено Решением Экономического совета СНГ от 14 июня
2018 г. [Электронный ресурс] // Единый реестр правовых актов и других документов Содружества Независимых Государств. URL : http:// cis.minsk.by/reestr/ru/index.html\#reestr/view/ text?doc=5810 (дата обращения: 05.06.2019).

\title{
Library Space of the CIS Countries as a Self-organizing System: Research Methodology
}

\author{
Natalia P. Igumnova, \\ Russian State Library, 3/5 Vozdvizhenka Str., Moscow, 119019, Russia \\ ORCID 0000-0002-2741-5244 \\ E-mail: IgumnovaNP@rsl.ru
}

\begin{abstract}
The article reveals the research methodology of the library space of the Commonwealth of Independent States (CIS) based on the theory of self-organization (synergetics). Synergetics as the direction of post-non-classical science was developed at the end of the last - the beginning of the new Millennium in the works of a number of researchers who proved the universality of this methodology and its applicability to the study of processes occurring in society. However, until the 2000s, this methodology did not get worthy application in the library science. The relevance of this study is that the modern library science requires a new worldview-methodological approach to the investigation of processes taking place in the cultural and library sphere, which will help to develop and enrich the successfully used method of system analysis. Based on this, the author sets the task to study the library space of the CIS as a self-organizing system that is in the process of evolution over a long historical period. The article considers the library space as a dynamically developing system of social nature. The author traces its cause-and-effect relations, conditions and factors in historical perspective and modern aspects. The concept of "library space of the CIS countries" arose after the disintegration of the Soviet Union in 1991 and as a result of formation of the CIS to refer to the form of interstate library interaction and cooperation. The article studies the library space of the CIS countries as a system of interaction of libraries formed in the post-Soviet period, the basis of which is their belonging to the Commonwealth of Independent States, within which the interstate relations of libraries are developing, basing on long historical and cultural ties between them; and the Russian language is the language of professional and interpersonal communication. The author presents the descriptive model of interaction system of libraries of the CIS countries with the main features and principles of construction. The article establishes that the CIS library space is characterized by features of a complex, open, dynamic self-organizing system. The methodological nature and theoretical philosophical significance of the article make it interesting for librarians, science theorists and cultural scientists.
\end{abstract}

Key words: Commonwealth of Independent States, CIS, library space, system model, historical-cultural ties, Russian language, conditions, factors, evolution and development, theory of library science, national libraries.

Citation: Igumnova N.P. Library Space of the CIS Countries as a Self-organizing System: Research Methodology, Bibliotekovedenie [Library and Information Science (Russia)], 2019, vol. 68, no. 4, pp. 383-390. DOI: 10.25281/0869-608X-2019-68-4-383-390. 


\section{References}

1. Moiseev N.N., Universum. Informatsiya. Obshchestvo [Universum. Information. Society]. Moscow, Ustoichivyi Mir Publ., 2001, 200 p.

2. Knyazeva E.N., Kurdyumov S.P. Osnovaniya sinergetiki. Chelovek, konstruiruyushchii sebya $i$ svoe budushchee [Foundations of Synergetics: A Man Constructing Himself and His-Own Future]. Moscow, KomKniga Publ., 2006, 232 p.

3. Astafyeva O.N. Synergetics, Philosophy, Culture, Gosudarstvennaya sluzhba [Public Administration], 2001, no. 2, pp. 32-43 (in Russ.).

4. Kagan M.S. Synergetics and Cultural Studies, Sinergetika i metody nauki [Synergetics Methods of Science]. St. Petersburg, Nauka Publ., 1998, pp. 201-219 (in Russ.).

5. Kapitsa S.P. Obshchaya teoriya rosta chelovechestva: skol'ko lyudei zhilo, zhivet i budet zhit' na Zemle [General Theory of Humanity Growth: How Many People Lived, Live and Will Live on Earth]. Moscow, Nauka Publ., 1999, 190 p. (Kibernetika: neogranichennye vozmozhnosti i vozmozhnye ogranicheniya [Cybernetics: Unlimited Possibilities and Possible Limitations]).

6. Stolyarov Yu.N. Synergetic Approach in Library, Bibliography and Book Sciences: When and Why It Is Needed, Biblioteka $i$ assotsiatsii v menyayushchemsya mire: novye tekhnologii i novye formy sotrudnichestva: trudy 10 yubileinoi mezhdunar. konf. "Krym 2003"
[Libraries and Associations in the Transient World: New Technologies and New Forms of Cooperation: Proceedings of the 10th Anniversary International Conference “Crimea 2003”]. Moscow, GPNTB Publ., 2003, vol. 2, pp. 760-763 (in Russ.).

7. Vokhrysheva M.G., Kuzmishina T.M. Modern Libraries Development Process from the Position of Synergetics, Nauchnye i tekhnicheskie biblioteki [Scientific and Technical Libraries], 2003, no. 6, pp. 4-13 (in Russ.).

8. Igumnova N.P. Evraziiskoe bibliotechnoe prostranstvo $v$ bibliotechnoi politologii: monografiya [Eurasian Library Space in Library Political Science: monograph]. Moscow, Pashkov Dom Publ., 2014, 133 p.

9. Bibliotechnye issledovaniya $v$ sisteme postneklassicheskoi nauki: problemno-orientirovannyi sbornik [Library Research in the System of Post-Non-Classical Science: problem-oriented collection]. Moscow, Pashkov Dom Publ., 2008, 271 p.

10. Regulation on the System of Interlibrary Loan and Document Delivery: Approved by the Decision of the CIS Economic Council of June 14, 2018, Edinyi reestr pravovykh aktov i drugikh dokumentov Sodruzhestva Nezavisimykh Gosudarstv [Unified Register of Legal Acts and Other Documents of the Commonwealth of Independent States]. Available at: http:// cis.minsk.by/reestr/ru/index.html\#reestr/view/ text?doc $=5810$ (accessed 05.06.2019) (in Russ.).

Редакция журнала «Библиотековедение» поздравляет

\section{Наталию Петровну ИГУМНОВУ с юбилеем!}

Дорогая Наталия Петровна!

Всегда с нетерпением ждем Ваших публикаций в журнале «Библиотековедение». Как один из самых уважаемых авторов, профессионал с большим жизненным и научным опытом, Вы помогаете нам и нашим читателям ориентироваться в сложных и актуальных теоретико-методологических вопросах библиотековедения, развития научных исследований библиотечноинформационной деятельности на постсоветском пространстве, заостряя внимание на важных, дискуссионных проблемах. Темы, к которым Вы обращаетесь, являются междисциплинарными и многоконтекстными, раскрываются на высоком научном уровне, формируют понимание значимости объединения усилий, направленных на сохранение культурного наследия народов Содружества Независимых Государств. От всей души благодарим Вас за сотрудничество с редакичиеи, внимательное и дружеское отношение кжурналу, за мастерство и неравнодушие автора, эксперта и рецензента.

Желаем Вам здоровья, творческого вдохновения, новых востребованных произведений. Надеемся на дальнейшее сотрудниество! 